\title{
Tornar-se pai na Unidade de Cuidados Intensivos Neonatal: revisáo integrativa
}

\author{
Bruna de Souza Lima Marskia ${ }^{a}$ Natália Custodio ${ }^{a}$, Flávia Corrêa Porto de Abreu ${ }^{b}$, \\ Débora Falleiros de Melloc, Monika Wernet ${ }^{\mathrm{a}}$ \\ ${ }^{a}$ Departamento de Enfermagem, Universidade Federal de São Carlos - UFSCar, São Carlos, SP, Brasil. \\ bPrograma de Pós-Graduação em Enfermagem, Universidade Federal de São Carlos - UFSCar, \\ São Carlos, SP, Brasil. \\ 'Departamento de Enfermagem, Universidade de São Paulo - USP, Ribeirão Preto, SP, Brasil.
}

\begin{abstract}
Resumo: A prematuridade e o baixo peso ao nascer são situações prevalentes de hospitalização da criança em Unidades de Cuidados Intensivos Neonatais (UCIN) no Brasil. A hospitalização da criança logo após o nascimento impõe separação precoce dos pais com desdobramentos para o desenvolvimento da maternidade e de sua paternidade. O objetivo deste estudo foi conhecer as produções científicas nacionais e internacionais, publicadas no período de 2007 a junho de 2012, abrangendo aspectos que caracterizam o tornar-se pai da criança nascida prematura e/ou baixo peso internadas na UCIN e identificar núcleos promotores do desenvolvimento da paternidade nessa situação. Trata-se de revisão integrativa da literatura, a partir das evidências de treze artigos científicos. Os resultados apontam a carência de apoio profissional ao pai da criança nascida pré-termo e/ou de baixo peso hospitalizadas na UCIN, especialmente pela desconsideração nas relações com os profissionais. Tais aspectos foram explorados através dos seguintes grupos temáticos: Necessidades e menosprezo; Proximidade; Transformação e cotidiano; Pai e equipe da UCIN; A paternidade após a consumação da alta hospitalar. As relações com os profissionais ganham destaque como núcleo de promoção da paternidade nesse contexto tendo em vista um cuidado integral à saúde da criança.
\end{abstract}

Palavras-chave: Prematuro, Unidades de Terapia Intensiva Neonatal, Alta do Paciente.

\section{Becoming a father in Neonatal Intensive Care Unit: an integrative review}

\begin{abstract}
Prematurity and low birth weight are prevalent cases of children hospitalized in Neonatal Intensive Care Units (NICU) in Brazil. The hospitalization of a child shortly after birth requires early separation from parents with ramifications for the development of maternity and paternity. This study has the objective to know the national and international scientific productions, published between 2007 and June 2012, addressing the aspects of becoming a father of a premature and/or low birth weight infant admitted in NICUs and to identify core promoters to the development of paternity in this situation. The results express lack of professional support to the father of the child born premature and/or with low birth weight hospitalized in NICUs, especially for disregarding the relationships with professionals. Such aspects were explored by the following thematic groups: Needs and contempt; Proximity; Transformation and every day life; Fathers and the NICU's staff; and Paternity after hospital discharge. Relationships with professionals gain prominence as a hub for promoting fatherhood in this context with a view to comprehensive health care of children.
\end{abstract}

Keywords: Premature Infant, Intensive Care Units Neonatal, Patient Discharge.

Autor para correspondência: Bruna de Souza Lima Marski, Universidade Federal de São Carlos, Rodovia Washington Luís, Km 235, SP-310, CEP 13565-905, São Carlos, SP, Brasil, e-mail: bmarski@gmail.com

Recebido em Jan. 16, 2014; $1^{\text {a }}$ Revisão em Maio 13, 2014; $2^{\text {a }}$ Revisão em Set. 15, 2014; Aceito em Jan. 6, 2015. 


\section{Introdução}

$\mathrm{Na}$ atualidade, a emergência de uma nova figura paterna tem sido observada (AIELLO; CIA; WILLIAMS, 2005), expressando maior afetividade e participação nos cuidados e na vida dos filhos (AIELLO; CIA; WILLIAMS, 2005; COELHO; FREITAS; SILVA, 2007), com intenção de amparo e proteção ao mesmo (SILVA; SILVA, 2009). O estabelecimento do papel paterno é um processo contínuo sob a influência de interaçôes sociais, em que as relaçôes estabelecidas com a criança detêm uma representatividade diferenciada (CREPALDI et al., 2006).

No Brasil, a prematuridade (nascimento com idade gestacional menor que 37 semanas) e o baixo peso ao nascer (peso menor que $2.500 \mathrm{~g}$ ) estáo entre as causas prevalentes de hospitalização em Unidade de Cuidados Intensivos Neonatal - UCIN (ROCHA et al., 2006). A hospitalização da criança logo após o nascimento impóe separação precoce dos pais com desdobramentos para o desenvolvimento da maternidade e paternidade.

As UCINs tendem a impor restriçôes de contato e interaçâo entre os pais e a criança e ofertam um incipiente acolhimento das necessidades paternas, apesar do reconhecimento da importância de sua inclusão nesse contexto (AAGAARD; HALL, 2008). Consoante a isso, identifica-se um crescente interesse na experiência do pai na UCIN (COSTA; PADILHA; MONTICELLI, 2010).

O presente estudo teve como objetivo conhecer as produçôes científicas nacionais e internacionais, publicadas no período de 2007 a junho de 2012, abrangendo aspectos que caracterizam o tornar-se pai da criança nascida prematura e/ou baixo peso internadas na UCIN e identificar núcleos promotores do desenvolvimento da paternidade nessa situação.

\section{Material e método}

Trata-se de uma revisão integrativa da literatura, com artigos qualitativos acerca da experiência do pai na UCIN. A revisão integrativa é um método que contribui com a prática clínica e favorece a compreensão mais densa de um fenômeno a partir do agrupamento de conhecimentos produzidos por pesquisas primárias (MENDES; SILVEIRA; GALVÃO, 2008).

De acordo com esse método, a primeira etapa envolve a seleçấo do tema e a formulação do problema. Com isso, a proposição foi de integrar o conhecimento disponível à luz das seguintes questôes:
"Como é para o pai a experiência e o tornar-se pai de filho prematuro e/ou de baixo peso na UCIN? Quais suas necessidades? Como o apoio a ele pode ser desenvolvido?".

A etapa seguinte consistiu no estabelecimento de critérios para inclusão e exclusão de estudos, bem como a busca na literatura científica. Os critérios de inclusão utilizados foram: ser artigo original de abordagem qualitativa; veicular conhecimentos acerca da experiência do pai na UCIN; estar escrito em inglês ou português; ter sido publicado entre os anos de 2007 a junho de 2012. Tal recorte de período deve-se ao fato do ano de 2007 ter veiculado reflexos acerca da regulamentaçáo da licença-paternidade e apresentação do Projeto Lei do Senado n. 666 de 2007 (BRASIL, 2007), o qual ainda está em implementação. Os critérios de exclusão adotados foram: não ter resumo disponível e acesso on-line livre na íntegra; não ter em seus resultados contribuições para as perguntas estabelecidas na revisão; não possuir o caminho metodológico claramente descrito.

As bases de dados eletrônicas Literatura LatinoAmericana e do Caribe em Ciências da Saúde (LILACS) e Medical Literature and Retrieval System On Line (MedLINE) foram selecionadas e a busca junto às mesmas ocorreu a partir da adoção dos descritores: unidades de terapia intensiva neonatal, alta do paciente e prematuro, combinados a partir da lógica boleana "and" em díade com o descritor pai. Identificou-se um total de 87 referências.

Inicialmente, procedeu-se à leitura dos resumos por dois pesquisadores e, após essa etapa, os não indicados eram refutados e os indicados eram designados a uma outra dupla de pesquisadores para sua leitura. Nesse processo, da amostra inicial de 87 artigos, 8 artigos atenderam os critérios de inclusão e foram submetidos aos processos analíticos. Além disso, foram incluídos mais 5 artigos obtidos por busca manual nas próprias referências dos artigos inicialmente selecionados.

Foi realizada a leitura dos artigos selecionados na íntegra, sendo coletadas informações com a utilização de um instrumento que continha os seguintes dados: referência bibliográfica, base de dados de indexação, objetivos, métodos e resultados que contemplavam os questionamentos da revisão. A leitura e análise dos artigos selecionados foram desenvolvidas separadamente, mas socializada no grupo de pesquisadores para só então ser incorporada ao corpo de resultados da revisão. $\mathrm{Na}$ existência de impasses, um terceiro pesquisador procedia à análise no intuito do consenso. 
Para extração das evidências científicas, leituras reiterativas do material coletado dos estudos primários foram realizadas, com o estabelecimento de temas, os quais direcionaram o agrupamento e apresentação dos resultados deste estudo.

\section{Resultados}

Dos 13 artigos analisados, em 8 o pai foi sujeito exclusivo, em 4 foi sujeito em conjunto com a mãe e em 1 a família constituiu-se como sujeito do estudo. A entrevista prevaleceu como estratégia de coleta de dados e a análise de conteúdo como método analítico. Destacaram-se três países na produção acerca da experiência do pai na UCIN: Brasil, com 5 artigos; Suécia, com 4 artigos; Canadá, com 3 artigos.

$\mathrm{Na}$ Tabela 1, estão apresentados os artigos analisados, de acordo com autores, ano, objetivos, sujeitos, técnica de coleta de dados, método e principais resultados.

Os principais resultados dos artigos selecionados foram analisados de forma descritiva, procedendo-se à categorização em grupos temáticos, a partir da identificação de aspectos de interesse e conceitos-chave do foco em estudo. Assim, foram agrupados sob os temas: Necessidades e menosprezo; Proximidade; Transformação e cotidiano; Pai e equipe da UCIN; A paternidade após a consumação da alta hospitalar.

\subsection{Necessidades e menosprezo}

O nascimento prematuro do filho e sua ida à UCIN é um choque para o pai (FEGRAN; HELSETH; FAGERMOEN, 2008; DANEREK; DYKES, 2008; BLOMQVIST et al., 2012), o que também o faz experienciar sentimentos de insegurança (CARVALHO et al., 2009; DANEREK; DYKES, 2008; BLOMQVIST et al., 2012) e de incertezas do real estado do filho (LEE et al., 2009). Ao vivenciar a situação de prematuridade do filho sente como se "o mundo tivesse caído" (DANEREK; DYKES, 2008) e tem a sensação de não assumir seu papel de pai (LUNDQVIST; WESTAS; HALLSTROM, 2007; LINDBERG; AXELSSON; OHRLING, 2008; BLOMQVIST et al., 2012). Além disso, ele não tem conhecimento e compreensão da situação (AROCKIASAMY; HOLSTI; ALBERSHEIM, 2008; DANEREK; DYKES, 2008), restringindo as tomadas de decisão na proteção da esposa e filho (LINDBERG; AXELSSON; OHRLING, 2008; LEE et al., 2009), uma vez que esta ação é concebida por ele como algo de sua responsabilidade (LEE et al., 2009; DEENEY et al., 2012).

O sentimento de menosprezo dos profissionais de saúde é percebido por ele desde os momentos periféricos ao parto, uma vez que os mesmos náo oferecem informaçóes diretivas a ele (DANEREK; DYKES, 2008; FEGRAN; HELSETH; FAGERMOEN, 2008). Sendo assim, busca por informaçôes ao longo do período do parto e nascimento do filho, permanecendo distante mas atento aos comportamentos dos profissionais, fazendo suas próprias interpretaçóes (FEGRAN; HELSETH; FAGERMOEN, 2008) quando, na verdade, desejava estar presente na sala de parto, para ver e acompanhar tudo de perto (FEGRAN; HELSETH; FAGERMOEN, 2008).

Assim, o pai sente-se solitário (CARVALHO et al., 2009) e limitado a ser um expectador do que está a acontecer (LUNDQVIST; WESTAS; HALLSTROM, 2007). Ao vivenciar esta situação surgem sentimentos de impotência, medo, ansiedade, insegurança, angústia, tristeza (LEE et al., 2009) e irrealidade (LUNDQVIST; WESTAS; HALLSTROM, 2007), determinando assim uma turbulência emocional dificultando a compreensão do pai da situação vivida (LUNDQVIST; WESTAS; HALLSTROM, 2007).

Obter informaçóes francas, honestas (AROCKIASAMY; HOLSTI; ALBERSHEIM, 2008; DANEREK; DYKES, 2008; SCHMIDT et al., 2012) e compreensíveis, com detalhamento da real situação e evolução do filho, é uma necessidade paterna (AROCKIASAMY; HOLSTI; ALBERSHEIM, 2008; SCHMIDT et al., 2012). Isto atenderia aos seus anseios e contribuiria para a ampliação dos seus conhecimentos sobre o que está acontecendo (AROCKIASAMY; HOLSTI; ALBERSHEIM, 2008; SCHMIDT et al., 2012). Para o pai a UCIN configura-se como um ambiente hostil e pouco acolhedor e o uso de aparelhagem traduz a ele gravidade da situação do filho (CARVALHO et al., 2009; BLOMQVIST et al., 2012). Diante disso, concebe o prematuro como frágil, com risco de morte (CARVALHO et al., 2009) considera as possibilidades de sequelas (DANEREK; DYKES, 2008).

A falta de informações compreensíveis e honestas potencializa as incertezas e os sentimentos negativos no pai, relacionada com o incipiente acolhimento e interação com os profissionais de saúde da UCIN (CARVALHO et al., 2009).

As informações transmitidas pelos profissionais de saúde são fundamentais no desempenho do papel de pai e do mediador entre mãe e criança (LEE et al., 2009) e entre o hospital e o restante da família. Veicular informaçôes traz desconforto ao pai, quando há aqueles que evitam contato com amigos e familiares para não precisar exercê-lo (AROCKIASAMY; HOLSTI; ALBERSHEIM, 2008). 


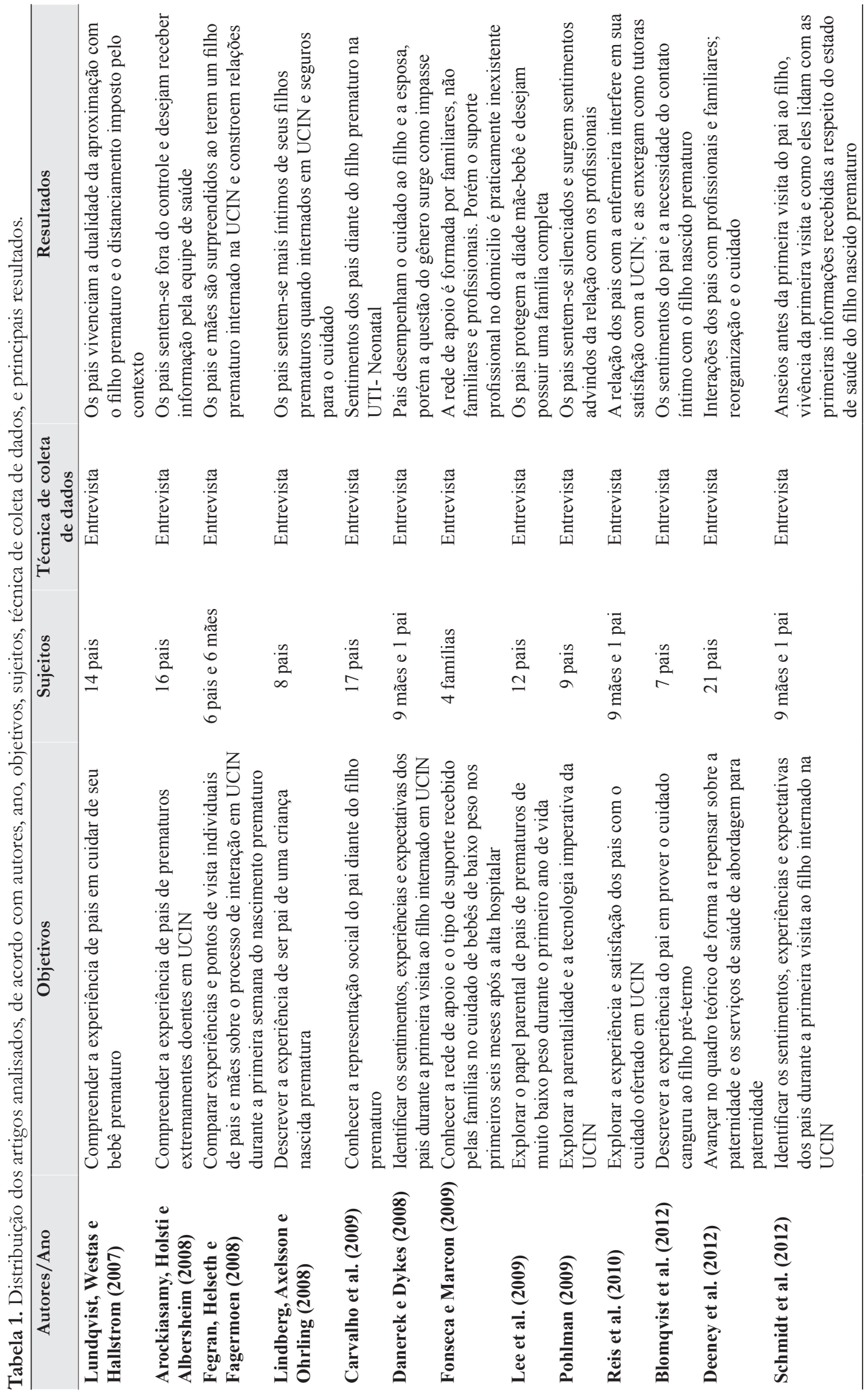




\subsection{Proximidade}

O pai deseja e busca interaçóes próximas com o filho durante o período de internação (LUNDQVIST; WESTAS; HALLSTROM, 2007; BLOMQVIST et al., 2012), e ter oportunidade de contato íntimo (LUNDQVIST; WESTAS; HALLSTROM, 2007; LINDBERG; AXELSSON; OHRLING, 2008; BLOMQVIST et al., 2012). Destaca que carregar o filho no colo (LINDBERG; AXELSSON; OHRLING, 2008), ter oportunidade do contato pele a pele precoce (FEGRAN; HELSETH; FAGERMOEN, 2008; DANEREK; DYKES, 2008; BLOMQVIST et al., 2012) e ser permitido pernoitar com o filho na UCIN (LUNDQVIST; WESTAS; HALLSTROM, 2007; BLOMQVIST et al., 2012) são ações que promovem vínculo, satisfação, segurança (FEGRAN; HELSETH; FAGERMOEN, 2008; DANEREK; DYKES, 2008; BLOMQVIST et al., 2012) e alívio de preocupações (FEGRAN; HELSETH; FAGERMOEN, 2008; BLOMQVIST et al., 2012), além de familiarizá-lo com filho (LINDBERG; AXELSSON; OHRLING, 2008; BLOMQVIST et al., 2012) e de ampliar o senso de família (LINDBERG; AXELSSON; OHRLING, 2008) e de pai (BLOMQVIST et al., 2012).

Frente a esse cenário, o pai busca vincular-se ao filho durante a hospitalização da criança especialmente por meio de conversas (LEE et al., 2009; POHLMAN, 2009). Alguns autores afirmam que sentir-se pai requer segurar, tocar, conversar (LEE et al., 2009; BLOMQVIST et al., 2012), acompanhar a progressão do filho, onde o peso é um parâmetro representativo (CARVALHO et al., 2009).

Enquanto que ver o filho pela primeira vez representa o reconhecimento da real situaçáo do mesmo e contribui para a apropriaçáo da paternidade, por promover certa tranquilidade, além dos sentimentos de amor, superação e afeto (SCHMIDT et al., 2012). Isto fomenta seu desejo de fornecer carinho, conforto e segurança para o filho (BLOMQVIST et al., 2012; SCHMIDT et al., 2012). Em consonância, lida com o distanciamento físico do filho, quando a incubadora representa uma barreira (LEE et al., 2009).

\subsection{Transformação e cotidiano}

O pai, frente ao nascimento e hospitalização do filho na UCIN, transforma seu cotidiano, tanto para atender as necessidades da família, em especial no cuidado do filho pré-termo, quanto para suprir as necessidades dos demais filhos (AROCKIASAMY; HOLSTI; ALBERSHEIM, 2008; LINDBERG; AXELSSON; OHRLING, 2008; DANEREK;
DYKES, 2008; FONSECA; MARCON, 2009) e esposa (AROCKIASAMY; HOLSTI; ALBERSHEIM, 2008; DANEREK; DYKES, 2008). Tem dificuldade de articular todas as demandas (DANEREK; DYKES, 2008), pois tende a ser superprotetor (LINDBERG; AXELSSON; OHRLING, 2008), dar baixa prioridade a suas próprias necessidades (LUNDQVIST; WESTAS; HALLSTROM, 2007) e comportar-se sob a crença de que pai não pode chorar, tem que ser emocionalmente estável (FEGRAN; HELSETH; FAGERMOEN, 2008) e forte (DEENEY et al., 2012).

No cotidiano, suas rotinas são afetadas e a noção de tempo e espaço fica comprometida (LUNDQVIST; WESTAS; HALLSTROM, 2007). Torna-se dependente de outras pessoas, especialmente quando a esposa ainda está internada (LUNDQVIST; WESTAS; HALLSTROM, 2007).

Por ser o provedor financeiro da família, alguns impasses são experienciados por querer participar no cuidado do filho e não poder (DEENEY et al., 2012). Assim, o trabalho representa oportunidade para desestressar (AROCKIASAMY; HOLSTI; ALBERSHEIM, 2008), porém a plenitude do mesmo náo é alcançada pelo fato de seu pensamento estar na criança (AROCKIASAMY; HOLSTI; ALBERSHEIM, 2008), e entende que o trabalho gera perda de oportunidades de estar com o filho (AROCKIASAMY; HOLSTI; ALBERSHEIM, 2008) e esposa (DANEREK; DYKES, 2008).

Ter apoio do empregador para o enfrentamento do nascimento prematuro de um filho e as demandas advindas disto é aspecto facilitador (DANEREK; DYKES, 2008), fato apontado especificamente num estudo realizado na Suécia que, quanto maior for a condição socioeconômica, maior a probabilidade do pai se fazer presente na UCIN, pois, em função de ter certa estabilidade financeira, tem maiores possibilidades de negociação (DEENEY et al., 2012). Além disto, o suporte mútuo entre os pais (pai e mãe) representa apoio emocional (AROCKIASAMY; HOLSTI; ALBERSHEIM, 2008; LINDBERG; AXELSSON; OHRLING, 2008; FONSECA; MARCON, 2009), promove enfrentamento das tristezas (LINDBERG; AXELSSON; OHRLING, 2008) e mutualidade diante das conquistas (LINDBERG; AXELSSON; OHRLING, 2008) ao longo da jornada do filho internado na UCIN.

A religiáo desponta como apoio para alguns pais por trazer tranquilidade, segurança e calma (AROCKIASAMY; HOLSTI; ALBERSHEIM, 2008; CARVALHO et al., 2009), além de contribuiçôes para a tomada de decisóes (AROCKIASAMY; HOLSTI; ALBERSHEIM, 2008) e aumento da 
esperança na superação do estado crítico do filho (CARVALHO et al., 2009). Tal aspecto ancora-se especialmente no entendimento de que o desenrolar da situação ocorre conforme a vontade divina (AROCKIASAMY; HOLSTI; ALBERSHEIM, 2008).

Obter informaçóes junto a parentes, profissionais e amigos para estabelecer um plano de ação que garanta a proteção da mãe e criança também é ação desempenhada pelo pai (LEE et al., 2009). Neste contexto, receber a ajuda nas tarefas da casa é apontado como relevante (FEGRAN; HELSETH; FAGERMOEN, 2008; BLOMQVIST et al., 2012), quando os sogros (DANEREK; DYKES, 2008), outros membros da família e amigos (BLOMQVIST et al., 2012) são recursos considerados.

\subsection{Pai e equipe profissional}

O pai sente-se desconsiderado da UCIN, quase "um alguém" (AROCKIASAMY; HOLSTI; ALBERSHEIM, 2008), pois o acolhimento e socializaçáo experienciados são incipientes (BLOMQVIST et al., 2012; DEENEY et al., 2012) e implicam em dificuldades de compreensão de sua função no cuidado da criança (LUNDQVIST; WESTAS; HALLSTROM, 2007; BLOMQVIST et al., 2012).

Fica estressado e frustrado nas visitas, pois não recebe informaçóes suficientes do que pode ou não fazer (BLOMQVIST et al., 2012). Além disto, a incubadora traz a compreensão de que ele deve apenas observar o filho (LEE et al., 2009), ato reforçado pelo medo de transmitir infecçôes (LEE et al., 2009).

A equipe profissional demonstra insensibilidade diante dos esforços paternos de vinculação com a criança (LINDBERG; AXELSSON; OHRLING, 2008; POHLMAN, 2009), especialmente por concentrar sua atenção no monitoramento dos equipamentos tecnológicos em detrimento ao relacionamento interpessoal (POHLMAN, 2009). Apesar disto, o pai considera a equipe como a mais preparada para exercer o cuidado do filho do que ele próprio (LUNDQVIST; WESTAS; HALLSTROM, 2007) e, em adição, o controle em relaçáo à criança por ela exercido traz, para alguns pais, segurança (AROCKIASAMY; HOLSTI; ALBERSHEIM, 2008; BLOMQVIST et al., 2012).

Frente ao contexto acima, há pais que decidem se retirar do cenário da UCIN (AROCKIASAMY; HOLSTI; ALBERSHEIM, 2008), e outros se sentem fisicamente presentes, mas emocionalmente distantes do filho (LUNDQVIST; WESTAS; HALLSTROM, 2007). Porém, a segurança daqueles que permanecem por longo período na UCIN aumenta e, com ela, a certeza de que o filho está sendo bem cuidado (LINDBERG; AXELSSON; OHRLING, 2008).

Apesar disto, quer ter açóes de cuidado junto ao filho, quando se destacam: levar o leite ordenhado pela esposa para a UCIN (LEE et al., 2009) e alimentar o filho por sonda (DANEREK; DYKES, 2008).

Contudo, experienciam impotência na proteção do filho, com sentimentos de não estarem cumprindo o papel de pai (LUNDQVIST; WESTAS; HALLSTROM, 2007). E, para se manterem resilientes, ancoram-se em pensamentos otimistas (AROCKIASAMY; HOLSTI; ALBERSHEIM, 2008), promovendo controle da situação e tomadas de decisóes (AROCKIASAMY; HOLSTI; ALBERSHEIM, 2008).

Tem como positivas as respostas diretas dos profissionais (AROCKIASAMY; HOLSTI; ALBERSHEIM, 2008) e valoram a forma como estes interagem e se comunicam com ele e com sua família (AROCKIASAMY; HOLSTI; ALBERSHEIM, 2008). Há reconhecimento daqueles que, além de conhecimento teórico, detêm habilidades relacionais, pois desejam relações mais horizontalizadas (AROCKIASAMY; HOLSTI; ALBERSHEIM, 2008). Neste sentido a rotatividade dos profissionais de enfermagem dificulta o estabelecimento de vínculo e confiança (POHLMAN, 2009), bem como a comunicação unidirecional adotada pela equipe (LINDBERG; AXELSSON; OHRLING, 2008).

A equipe de enfermagem faz coaçôes impositivas nas relaçôes com os pais e a atitude do enfermeiro é percebida como pouco humanizada, mas cumpridora de tarefas (POHLMAN, 2009). Em decorrência desta relação, o pai náo busca contato com a equipe para não incomodar a mesma (LINDBERG; AXELSSON; OHRLING, 2008).

Em contraponto, experiências de facilitação, tutoria e aprendizagem com enfermeiros promovem segurança para o cuidado do filho na UCIN, em decorrência da certeza de existência de uma supervisão próxima e cuidadosa na transferência de responsabilidade (REIS et al., 2010). Além disto, sente-se respeitado quando o enfermeiro acata e respeita sua opção de ser observador do cuidado profissional (REIS et al., 2010).

O conhecimento advindo das oportunidades de cuidado e proximidade com o filho na UCIN traz segurança, promove a autonomia para o cuidado e gera, simultaneamente, inseguranças frente à responsabilidade sentida (LINDBERG; AXELSSON; OHRLING, 2008). 
Ter oportunidade de tomadas de decisão compartilhadas contribui para o controle e confiança e diminui o medo (DANEREK; DYKES, 2008), contudo não se sente envolvido de fato no cuidado do filho (LINDBERG; AXELSSON; OHRLING, 2008), apesar do profissional explicitar permissão (LINDBERG; AXELSSON; OHRLING, 2008). O comum é deixar sob a responsabilidade do médico e equipe a decisão das condutas (DANEREK; DYKES, 2008), mesmo quando náo acolhidos (CARVALHO et al., 2009).

Durante a estada na UCIN tem sua aproximação com o filho intensificada por oportunidades de interação com a criança na incubadora ou em seu colo (LUNDQVIST; WESTAS; HALLSTROM, 2007). Sente-se motivado e estimulado pela equipe a interagir e cuidar do filho, e percebe que os profissionais agem desta forma no intuito de familiarizá-lo com a criança e empoderá-lo para o seu cuidado (DANEREK; DYKES, 2008).

\subsection{A paternidade após a consumação da alta hospitalar}

Quando em domicílio com o filho, sente-se mais autônomo e confiante no seu papel de pai (LINDBERG; AXELSSON; OHRLING, 2008), fortalecendo o senso de família (LEE et al., 2009), pois está próximo do filho e sabe que o estado de saúde da criança está mais consolidado (LEE et al., 2009).

O pai tem inseguranças em relação ao cuidado da criança em domicílio e associa as mesmas à falta de oportunidade de participaçáo no processo gestacional e na UCIN (FONSECA; MARCON, 2009), bem como ao comportamento materno de assumir o cuidado do filho como centro do seu viver (DEENEY et al., 2012). Em relação a este último, o pai precisa disputar espaço com a esposa para conseguir ter participação no cuidado do filho (DEENEY et al., 2012).

Porém, concebe que pelo fato de ser pai de criança nascida prematura possui um envolvimento diferenciado com a mesma e com sua recuperação (LINDBERG; AXELSSON; OHRLING, 2008). Isto repercute positivamente no papel de pai em termos de preparo e imersão na experiência da paternidade (LINDBERG; AXELSSON; OHRLING, 2008). Além disto, aqueles pais que mantiveram interações ativas com o filho ao longo da gestação conseguem perceber a responsividade do filho a sua presença, o que retroalimenta mais seu sentimento de pai (POHLMAN, 2009).

\section{Discussão}

A presente revisáo integrativa assinala a carência de apoio profissional ao pai da criança nascida pré-termo e/ou de baixo peso hospitalizadas na UCIN, especialmente pela desconsideração nas relaçóes com os profissionais. Assim, sugere que isso pode afetar a qualidade do cuidado a ele ofertado e o desenvolvimento do papel paterno.

A interação com os profissionais desponta-se como um desafio neste contexto, o que vem sendo sinalizado por outros estudos (TRONCHIN; TSUNECHIRO, 2005; GAÍVA; SCOCHI, 2005). A sintonia e sensibilidade do profissional para com a situação vivida pelo pai estão incipientemente presentes. Os resultados denotam estar o pai praticamente invisível aos olhos dos profissionais, o que o faz se sentir como mero expectador, além do contato pai-filho dificultado. Há poucas informaçôes e estratégias de apoio (TRONCHIN; TSUNECHIRO, 2006), bem como compreensão de forma contextualizada e congruente com a especificidade da experiência de cada pai (CONZ; MERIGUI; JESUS, 2009).

Entretanto, defende-se, no Brasil, como norteadores do cuidado, a integralidade e humanização (BRASIL, 2003). A proposta brasileira de humanização na saúde tem como objetivo fundamental aprimorar as relações entre profissionais, entre usuários e profissionais e entre hospital e comunidade, em prol da melhoria da qualidade da atençáo prestada. Contudo, a atitude dos profissionais ainda demonstra um despreparo para tanto, uma vez que o olhar do profissional volta-se para partes cada vez menores do corpo e, dessa forma, negligencia outros aspectos envolvidos no processo de cuidar, em detrimento de uma perspectiva de trabalho valorizadora da prática clínica, tecnificada e rotinizada (TRONCHIN; TSUNECHIRO, 2005). Carece-se investir em transformaçóes de valores no cenário da saúde, onde as pessoas e suas experiências sejam o centro de preocupação do profissional, com vistas a um olhar integrador (TRONCHIN; TSUNECHIRO, 2005; BARROS; GOMES, 2011). É inegável o valor do aparato tecnológico na UCIN como fator contribuinte para o cuidado, mas integrado a ela deve-se fazer presente o processo relacional, assim como o afeto, a atenção aos familiares e a solidariedade, promovendo as pessoas sob cuidados profissionais a sujeitos de direitos, portadores de histórias e de valores (TRONCHIN; TSUNECHIRO, 2005), o que se estende ao pai. 
Isto implica em incorporar um ato de cuidar abrangente, sustentado no referencial do relacionamento pessoal, agregando às açóes cuidativas em enfermagem a atenção pelo outro, o comprometimento para com o outro, o respeito e a empatia (CONZ; MERIGUI; JESUS, 2009, p. 854).

Ainda, neste contexto, cabe destacar a necessidade de se transpor a concepção de ser a criança e a mãe como principais ou únicos sujeitos de cuidado profissional, com exclusão dos irmãos, avós, e dos pais, dentre outros sujeitos que são igualmente afetados pela situação. Quando os profissionais estáo imbuídos de atitudes de reconhecimento ao pai na UCIN, esse tem seu processo de tornar-se pai facilitado e tende a promover a coconstrução do cuidado, a qual favorece açóes mais consonantes com a especificidade das necessidades de cada sujeito (TRONCHIN; TSUNECHIRO, 2006), e cada pai, além de valorar e acolher sentimentos como medo, angústia, insegurança e ansiedade sentidos por ele.

Com isso, o diálogo entre pai e profissional, na perspectiva de uma tecnologia leve de cuidado (TRONCHIN; TSUNECHIRO, 2005; SILVA; ALVIM; FIGUEIREDO, 2008), pode ser compreendido como uma ferramenta para um cuidar mais humanizado na UCIN. Perceber o momento de falar, o que falar, o saber ouvir e o compartilhar de ideias, sentimentos e decisóes são competências e habilidades necessárias aos profissionais.

Nesse sentido, a formação de graduação em enfermagem (CONZ; MERIGUI; JESUS, 2009), e podemos dizer para os demais profissionais na área de saúde que, assim como os enfermeiros também podem estar envolvidos na hospitalização de uma criança nascida prematura, devem rever seus currículos, de forma a ampliar a abordagem de temas concernentes às relaçôes humanas ao longo do processo saúde-doença, bem como nas questóes relativas às práticas com famílias, cujo corpo de conhecimento está amplamente explorado nos estudos de Enfermagem de Família.

Os resultados sugerem investigações científicas que foquem as relaçóes dos profissionais com os pais, bem como o entendimento dos profissionais em relação à participação do pai na UCIN, com contribuiçóes para o desenvolvimento da paternidade, trazendo mais dimensões para transformaçóes do cenário encontrado.

\section{Considerações finais}

A presente revisão permitiu identificar que os processos relacionais com os profissionais de saúde despontam como pouco acolhedores ao pai, destacando que a desinformação é expressiva, determina sentimentos de menosprezo e afeta o tornar-se pai da criança hospitalizada em contexto de prematuridade. A desinformação experienciada potencializa percepçóes negativas em relação à prematuridade e à UCIN e consequente insegurança em relação ao futuro do filho, ao comportamento esperado dele na UCIN e a suas possibilidades de cuidado ao filho.

O pai almeja a proximidade do filho, porém tem raras oportunidades de contato com o mesmo, pois os profissionais não são sensíveis às suas manifestaçôes. Além disso, seu cotidiano é afetado com as demandas advindas da internação do filho e surgem impasses em relação ao papel esperado, sentindo-se como depositário do provimento financeiro da família.

Os principais apoios nessa trajetória são: o suporte mútuo entre o casal, a religião, a família extensa e o acolhimento profissional quando é experienciado. A alta da criança e sua ida ao domicílio contribuem para o estabelecimento da paternidade, contudo permanecem inseguranças no cuidado da criança.

Infere-se que alcançar a humanização da assistência na UCIN contribuiria significativamente com o ser pai de criança nascida prematura e/ou de baixo peso e isso perpassa pelo cuidado ofertado ao pai.

\section{Referências}

AAGAARD, H.; HALL, E. O. Mother's experiences of having a preterm infant in the neonatal care unit: a meta-synthesis. Journal of Pediatric Nursing, Denmark, v. 23, n. 3, p. e26-e36, 2008. http://dx.doi.org/10.1016/j. pedn.2007.02.003. PMid:18492543

AIELLO, A. L. R.; CIA, F.; WILLIAMS, L. C. A. Influências paternas no desenvolvimento infantil: revisão de literatura. Pscicologia Escolar e Educacional, Campinas, v. 9, n. 2, p. 225-233, 2005. http://dx.doi.org/10.1590/ S1413-85572005000200005.

AROCKIASAMY, V.; HOLSTI, L.; ALBERSHEIM, $S$. Fathers' experiences in the neonatal intensive care unit: a search for control. Pediatrics, Canadá, v. 121, n. 2, p. e215-e222, 2008. http://dx.doi.org/10.1542/ peds.2007-1005. PMid: 18182470

BARROS, M. E. B.; GOMES, R. S. Humanização do cuidado em saúde: de tecnicismos a uma ética do cuidado. Revista de Psicologia, Niterói, v. 23, n. 3, p. 641-658, 2011. 
BLOMQVIST, Y. T. et al. Kangaroo Mother Care helps fathers of preterm infants gain confidence in the paternal role. Journal of Advanced Nursing, Sweden, v. 68, n. 9, p. 1988-1996, 2012. http://dx.doi.org/10.1111/j.13652648.2011.05886.x. PMid:22111919

BRASIL. Ministério da Saúde. Política Nacional de Humanização. Brasília: Humaniza SUS, 2003. Disponível em: <http://portal.saude.gov.br/portal/saude/cidadao/ area.cfm?id_area=1342>. Acesso em: 10 fev. 2013.

BRASIL. Senado Federal. Projeto de Lei do Senado, no 666 de 2007. Regulamenta a licença-paternidade a que se refere o inciso XIX, do art. $7^{\circ}$, da Constituição Federal. Diário do Senado Federal, Poder Executivo, Brasília, DF, 22 nov. 2007.

CARVALHO, J. B. et al. Representação social de pais sobre o filho prematuro na Unidade de Terapia Intensiva Neonatal. Revista Brasileira de Enfermagem, Brasília, v. 62, n. 5, p. 734-738, 2009. http://dx.doi.org/10.1590/ S0034-71672009000500014. PMid:20552833

COELHO, E. A. C.; FREITAS, W. M. F.; SILVA, A. T. M. C. Sentir-se pai: a vivência masculina sob o olhar de gênero. Cadernos de Saúde Pública, Rio de Janeiro, v. 23, n. 1, p. 137-145, 2007.

CONZ, C. A.; MERIGUI, M. A. B.; JESUS, M. C. P. Promoção de vínculo afetivo na Unidade de Terapia Intensiva Neonatal: um desafio para as enfermeiras. Revista da Escola de Enfermagem da USP, São Paulo, v. 43, n. 4, p. 849-855, 2009. http://dx.doi.org/10.1590/S008062342009000400016 .

COSTA, R.; PADILHA, M. I.; MONTICELLI, M. Production of knowledge about the care given to newborns in neonatal IC: contribution of Brazilian nursing. Revista da Escola de Enfermagem da USP, São Paulo, v. 44, n. 1, p. 199-204, 2010. http://dx.doi.org/10.1590/ S0080-62342010000100028. PMid:20394239

CREPALDI, M. A. et al. A participação do pai nos cuidados da criança, segundo a concepção de mães. Psicologia em Estudo, Maringá, v. 11, n. 3, p. 579-587, 2006. http:// dx.doi.org/10.1590/S1413-73722006000300014.

DANEREK, M.; DYKES, A. K. A theoretical model of parents' experiences of threat of preterm birth in Sweden. Midwifery, Lund, v. 24, n. 4, p. 416-424, 2008. http://dx.doi.org/10.1016/j.midw.2006.07.011. PMid:17936459

DEENEY, K. et al. Experiences of fathering a baby admitted to neonatal intensive care: a critical gender analysis. Social Science Medical, Sheffield, v. 75, n. 6, p. 11061113, 2012.

FEGRAN, L.; HELSETH, S.; FAGERMOEN, M. S. A comparison of mothers' and fathers' experiences of the attachment process in a neonatal intensive care unit. Journal of Clinical Nursing, Norway, v. 17, n. 6, p. 810-816, 2008. http://dx.doi.org/10.1111/j.13652702.2007.02125.x. PMid:18279284
FONSECA, E. L.; MARCON, S. S. Rede de apoio às famílias de bebês de baixo peso após a alta hospitalar: um estudo qualitativo. Online Brazilian Journal of Nursing, Maringá, v. 8, n. 2, p. 11-19, 2009.

GAÍVA, M. A. M.; SCOCHI, C. G. S. A participação da família no cuidado ao prematuro em UTI neonatal. Revista Brasileira de Enfermagem, Brasília, v. 58, n. 4, p. 444-448, 2005. http://dx.doi.org/10.1590/S003471672005000400012. PMid:16514952

LEE, T. Y. et al. Assuring the integrity of the family: being the father of a very low birth weight infant. Journal of Clinical Nursing, Taipei, v. 18, n. 4, p. 512-519, 2009. http://dx.doi.org/10.1111/j.1365-2702.2008.02487.x. PMid:19192000

LINDBERG, B.; AXELSSON, K.; OHRLING, K. Adjusting to being a father to an infant born prematurely: experiences from Swedish fathers. Scandinavian Journal of Caring Sciences, Luleå, v. 22, n. 1, p. 79-85, 2008. http://dx.doi.org/10.1111/j.1471-6712.2007.00563.x. PMid:18269426

LUNDQVIST, P.; WESTAS, L. H.; HALLSTRÖM, I. From distance toward proximity: fathers lived experience of caring for their preterm infants. Journal of Pediatric Nursing, Lund, v. 22, n. 6, p. 490-497, 2007. http://dx.doi.org/10.1016/j.pedn.2007.04.008. PMid: 18036470

MENDES, K. D. S.; SILVEIRA, R. C. C. P.; GALVĀO, C. M. Revisão integrativa: método de pesquisa para a incorporação de evidências na saúde e na enfermagem. Texto e Contexto Enfermagem, Florianópolis, v. 17, n. 4 , p. 758-764, 2008.

POHLMAN, S. Fathering premature infants and the technological imperative of the neonatal intensive care unit: an interpretive inquiry. Advance in Nursing Science, St. Louis, v. 32, n. 3, p. E1-E16, 2009. http://dx.doi.org/10.1097/ANS.0b013e3181b0d68c. PMid:19707083

REIS, M. D. et al. Developing nurse/parent relationships in the NICU through negotiated partnership. Journal of Obstetric, Gynecologic and Neonatal Nursing, Greensboro, v. 39, n. 6, p. 675-683, 2010. http://dx.doi. org/10.1111/j.1552-6909.2010.01189.x.

ROCHA, R. C. L. et al. Prematuridade e baixo peso entre recém-nascidos de adolescentes primíparas. Revista Brasileira de Ginecologia e Obstetrícia, Rio de Janeiro, v. 28 , n. 9 , p. $530-535,2006$

SCHMIDT, K. T. et al. A primeira visita ao filho internado na Unidade de Terapia Intensiva Neonatal. Escola Anna Nery, Rio de Janeiro, v. 16, n. 1, p. 73-81, 2012. http://dx.doi.org/10.1590/S141481452012000100010 .

SILVA, D. C.; ALVIM, N. A. T.; FIGUEIREDO, P. A. Tecnologias leves em saúde e sua relação com o cuidado de enfermagem hospitalar. Escola Anna Nery, Rio 
de Janeiro, v. 12, n. 2, p. 291-298, 2008. http://dx.doi. org/10.1590/S1414-81452008000200014.

SILVA, L. J.; SILVA, L. R. Mudanças na vida e no corpo: vivências diante da gravidez na perspectiva afetiva dos pais. Escola Anna Nery, Rio de Janeiro, v. 13, n. 2, p. 393-401, 2009. http://dx.doi.org/10.1590/S141481452009000200022 .

TRONCHIN, D. M. R.; TSUNECHIRO, M. A. A experiência de tornarem-se pais de prematuro: um enfoque etnográfico. Revista Brasileira de Enfermagem, Brasília, v. 58, n. 1, p. 49-54, 2005. http://dx.doi.org/10.1590/ S0034-71672005000100009. PMid:16268283

TRONCHIN, D. M. R.; TSUNECHIRO, M. A. Cuidar e o conviver com o filho prematuro: a experiência do pai. Revista Latino-Americana de Enfermagem, Ribeirão Preto, v. 14, n. 1, p. 93-101, 2006. http:// dx.doi.org/10.1590/S0104-11692006000100013. PMid:16532245

\section{Contribuição dos Autores}

Bruna de Souza Lima Marski: Contribuição científica e intelectual efetiva para o estudo, concepção e delineamento, aquisição e interpretação dos dados, redação do texto. Natália Custodio e Flávia Corrêa Porto de Abreu: Contribuição científica e intelectual efetiva para o estudo, interpretaçáo dos dados, redação do texto. Débora Falleiros de Mello: Contribuição científica e intelectual efetiva para o estudo, revisão crítica. Monika Wernet: Contribuição científica e intelectual efetiva para o estudo, concepção e delineamento, redação do texto, revisão crítica. Todos os autores aprovaram a versão final do texto. 